\title{
EVALUATION OF CONSERVATIVELY TREATED LUMBAR DISC PROLAPSE USING MICHIGAN STATE UNIVERSITY (MSU) CLASSIFICATION
}

HeshamAly El Saghir, Yasser Mohsen Allam, Mahmoud El Sayed Nafady, Walid Ahmed El Nawawy*, Mohamed Ibrahim Abdelrazek

Department of Orthopedic Surgery and Traumatology, Orthopedic and Spine Surgery Specialist*, Faculty of Medicine, Alexandria University, Egypt

\begin{tabular}{|c|}
\hline $\begin{array}{l}\text { Lumbar disc prolapse is considered a worldwide health problem. Numerous studies } \\
\text { showed that conservative treatment yields similar outcome compared to surgical } \\
\text { treatment on the long term. To explain the spontaneous regression of disc prolapse } \\
\text { three theories were suggested. The first theory: shrinkage through dehydration and loss } \\
\text { of water content, the second theory: the tension applied by the posterior longitudinal } \\
\text { ligament provided there is no defect in annulus fibrosis, the third one: the resorption of } \\
\text { disc material of extruded parts by inflammatory reaction mediated by cytokines } \\
\text { release, macrophage infiltration and phagocytosis, enzymatic degradation, and } \\
\text { neovascularization. In this study, MSU classification was used as tool in evaluating the } \\
\text { change that happened in MRI of conservatively treated patients for at least } 6 \text { months. }\end{array}$ \\
\hline
\end{tabular}

\section{Aim of the work}

To evaluate patients suffering from lumbar disc prolapse treated conservatively using MSU classification.

\section{Patients and Methods}

32 patients with symptomatic lumbar disc prolapse treated according to conservative treatment program in spine unit in El-Hadara university hospital constituted the method of this study. MRI examination was done at presentation and
at least six months during follow up. MRI images were evaluated and classified at least six months during follow up. MRI images
using MSU (Michigan State University) Classification.

\section{Results}

After at least six months of follow up (mean \pm SD 15.59 months \pm 9.95 ), 21 patients $(65.6 \%)$ showed regression in their disc size, with only 15 of these cases $(46.9 \%)$ moved from higher grade to lower grade (downgrade) using the MSU classification. The level of agreement between classification changes and MRI changes in the present study was 0.421 , which reflects a moderate accuracy in describing these changes in MRI.

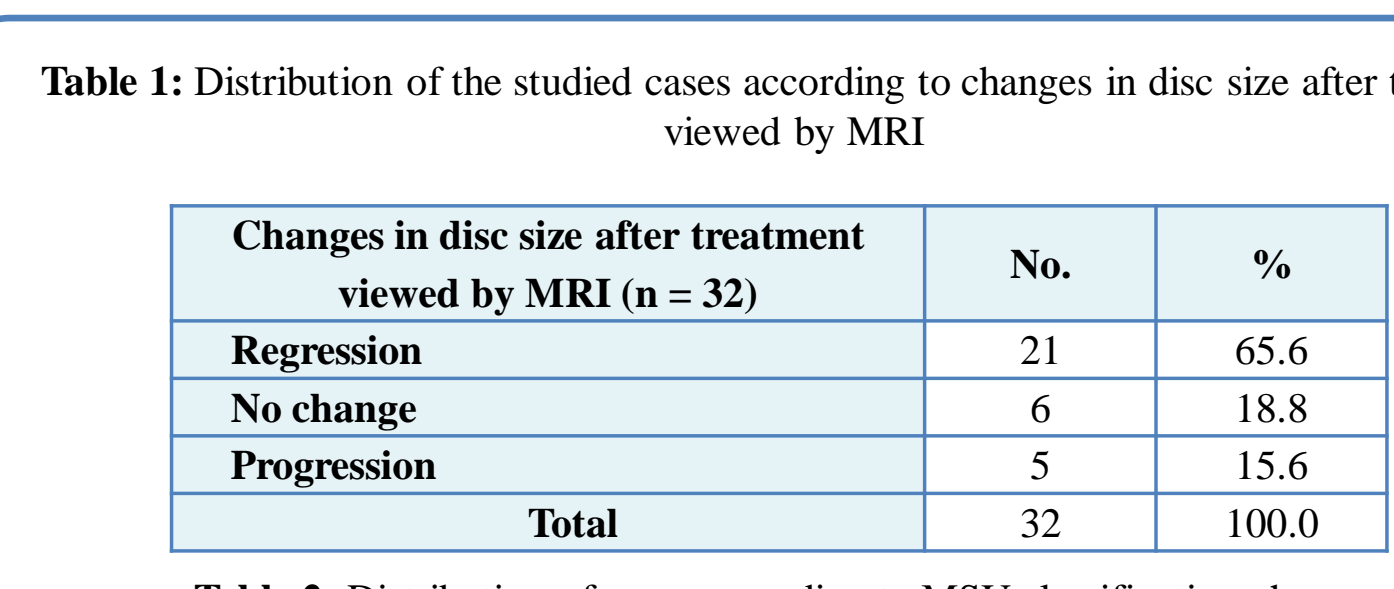

Table 2: Distribution of cases according to MSU classification changes

\begin{tabular}{|c|c|c|}
\hline MSU classification changes & No. & $\%$ \\
\hline Downgrade & 15 & 46.9 \\
\hline No change & 16 & 50.0 \\
\hline Upgrade & 1 & 3.1 \\
\hline Total & 32 & 100.0 \\
\hline
\end{tabular}

Table 3: Relation between MSU Classification changes and MRI changes after conservative treatment and level of agreement

\begin{tabular}{|c|c|c|c|c|c|c|}
\hline & \multicolumn{6}{|c|}{ MSU classification changes } \\
\hline & \multicolumn{2}{|c|}{$\begin{array}{l}\text { Downgrade } \\
(\mathbf{n}=15)\end{array}$} & \multicolumn{2}{|c|}{$\begin{array}{l}\text { No change } \\
(\mathrm{n}=16)\end{array}$} & \multicolumn{2}{|c|}{$\begin{array}{c}\text { Upgrade } \\
(\mathbf{n}=\mathbf{1})\end{array}$} \\
\hline & No. & $\%$ & No. & $\%$ & No. & $\%$ \\
\hline \multicolumn{7}{|l|}{$\begin{array}{l}\text { Changes in disc size after } \\
\text { treatment viewed by MRI }\end{array}$} \\
\hline Regression & 14 & 43.8 & 7 & 21.9 & 0 & 0.0 \\
\hline No change & 0 & 0.0 & 6 & 18.8 & 0 & 0.0 \\
\hline Progression & 1 & 3.1 & 3 & 9.4 & 1 & 3.1 \\
\hline Kappa (p) & \multicolumn{6}{|c|}{$0.421^{*}\left(<0.001^{*}\right)$} \\
\hline Level of agreement & & & oderate & greems & & \\
\hline
\end{tabular}

к: kappa test

*: Statistically significant at $p \leq 0.05$

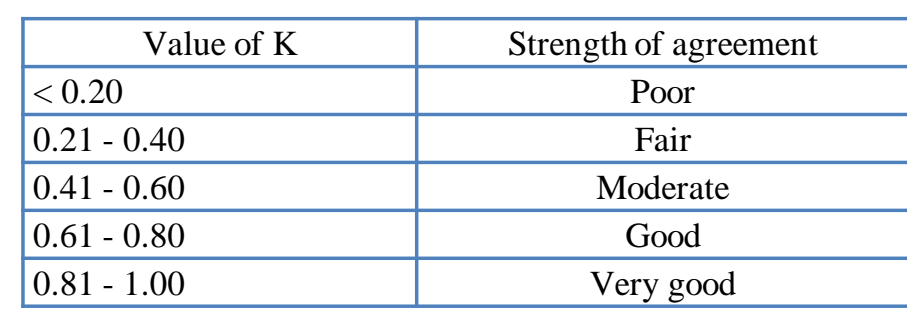

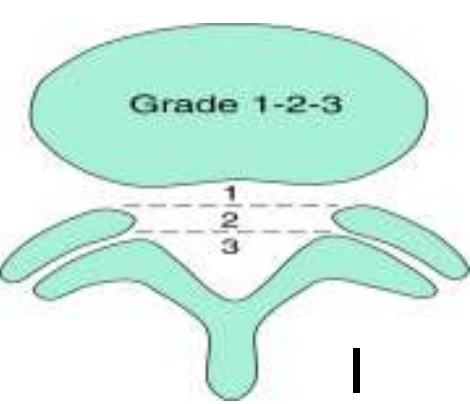
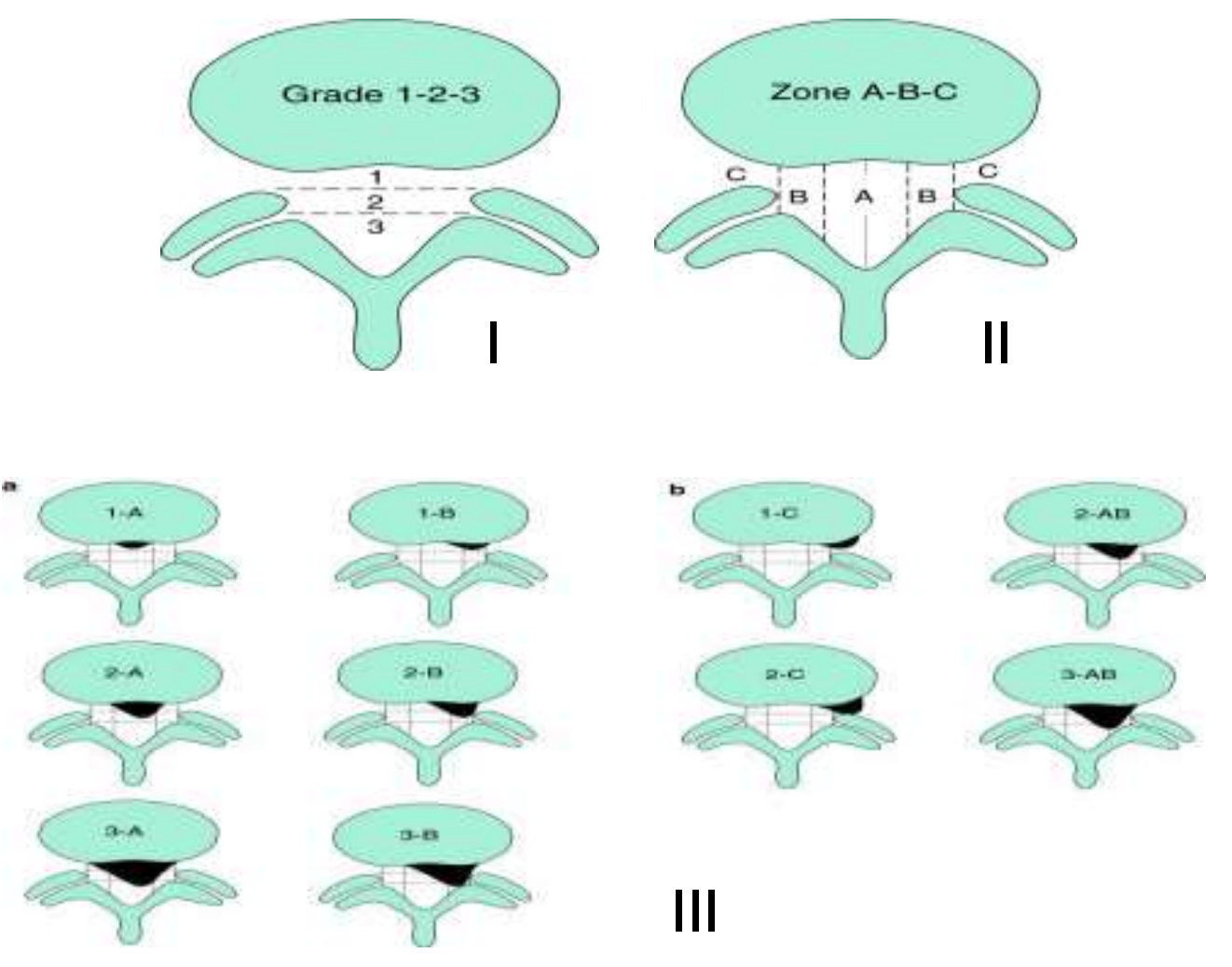

III

Figure : MSU classification:

Drading the disc hernintion for size,IIZZoning the disc for location, III) Combining size and location.

a) Lesions $2 \mathrm{~B}$ are commonly symptomatic. $3 \mathrm{~A}$ lesions are often seen in Caudaequina. b) Lesions $2 \mathrm{C}$ are the largest foraminal lesions. Lesions $2 \mathrm{AB}$ are quite common,

occurring on the line between zones A and B

\section{Conclusion}

MSU classification is simple and easy to apply as anatomical classification, but it has its limitations in evaluating MRI at follow up. It has a moderate sensitivity in describing disc size changes in MRI which means that it cannot evaluate some changes happening in MR of patients treated by conservative treatment.

$$
\begin{gathered}
20210 \text { Alexandria Faculty of Medicine } \\
\text { CC-BY-NC }
\end{gathered}
$$

